\title{
Kanamycin A
}

National Cancer Institute

\section{Source}

National Cancer Institute. Kanamycin A. NCI Thesaurus. Code C76151.

The major component of the kanamycin complex, an aminog lycoside antibiotic isolated from Streptomyces kanamyceticus, with antibacterial activity. 